\title{
Olivine: a supergreen fuel
}

\author{
Roelof D Schuiling
}

\begin{abstract}
The hydration and carbonation of olivine, the most common mineral on Earth, produce a large amount of heat. Unfortunately, the reaction is too slow for normal technological applications, but when thermally well isolated, most of this heat can be recovered, not only for space heating but even for the production of high-pressure steam. During the reaction, $\mathrm{CO}_{2}$ is sustainably sequestered. In this paper, a number of potential applications are described. Using the hydration and carbonation of olivine not only increases the energy production but also sequesters at the same time large volumes of $\mathrm{CO}_{2}$ that would otherwise be emitted, or would have to be removed by expensive technologies. The term "supergreen fuel" refers to the fact that this energy production is not associated with $\mathrm{CO}_{2}$ production, but quite the contrary, it even sequesters $\mathrm{CO}_{2}$ while producing energy.
\end{abstract}

\section{Review}

\section{Introduction}

Olivine is a mixed crystal of $\mathrm{Mg}_{2} \mathrm{SiO}_{4}$ and $\mathrm{Fe}_{2} \mathrm{SiO}_{4}$, in which the magnesium member is usually dominant. It is the major mineral in the mantle of the Earth. Plate-tectonic processes have pushed up enormous slabs of olivine-rich rocks from the mantle to the Earth's surface, where they can be mined in open pit mines. Their weathering, in case of excess fluid as in wet climates, proceeds according to the following reaction below:

$$
\begin{aligned}
\mathrm{Mg}_{2} \mathrm{SiO}_{4} & +4 \mathrm{CO}_{2}+4 \mathrm{H}_{2} \mathrm{O} \rightarrow 2 \mathrm{Mg}^{2+} \\
& +4 \mathrm{HCO}_{3}{ }^{-}+\mathrm{H}_{4} \mathrm{SiO}_{4}{ }^{0}
\end{aligned}
$$

By this and similar weathering reactions throughout the history of the Earth, $\mathrm{CO}_{2}$ was removed from the atmosphere. The resulting magnesium bicarbonate solutions are carried by rivers to the sea, where marine organisms (corals, shellfish, and plankton) convert them to carbonate rocks. This is the way by which $99.94 \%$ of all the $\mathrm{CO}_{2}$ that has leaked out of the planet has been sustainably captured in rocks [1]. This has saved us from the fate of our sister planet Venus, where weathering is impossible because Venus has no liquid water. All the $\mathrm{CO}_{2}$ that was ever emitted by Venus has stayed in the atmosphere, leading to a $\mathrm{CO}_{2}$ pressure of 85 bars and a surface temperature of $460^{\circ} \mathrm{C}$.

At present, the amount of $\mathrm{CO}_{2}$ produced by the burning of fossil fuels is so large that this weathering process cannot keep pace, so the $\mathrm{CO}_{2}$ content of the atmosphere is rising,

Correspondence: r.d.schuiling@uu.nl

Institute for Geosciences, Utrecht University, Budapestlaan 4, 3508, TA, Utrecht, The Netherlands causing probably a climate change and certainly an ocean acidification. Increasing the rate of weathering as well to reach a new balance is the straightforward answer to the problem of rising $\mathrm{CO}_{2}$ levels in the atmosphere [2].

\section{Exergy production from carbonation and hydration}

When there is no excess of fluids, a more or less closed system filled with olivine, $\mathrm{CO}_{2}$, and water in stoichiometric proportions reacts as follows:

$$
\begin{aligned}
2 \mathrm{Mg}_{2} \mathrm{SiO}_{4} & +1 \mathrm{CO}_{2}+2 \mathrm{H}_{2} \mathrm{O} \rightarrow \mathrm{Mg}_{3} \mathrm{Si}_{2} \mathrm{O}_{5}(\mathrm{OH})_{4} \\
& +\mathrm{MgCO}_{3}
\end{aligned}
$$

The products are serpentine (similar to clay minerals) and magnesite. It is a common knowledge that the baking of clays to make bricks and the burning of carbonates require a high energy input, so the reverse reaction should be exothermal. The thermodynamic data for the components of this reaction are presented in Table 1 [3].

The enthalpy of the reaction is $-169.1 \mathrm{~kJ} / \mathrm{mol} \mathrm{CO}_{2}$ or $0.47 \mathrm{~kJ} /$ gram of the stoichiometric mixture. As long as the water stays in the liquid state, the changes in the enthalpy of reaction as a function of temperature are minimal. With an average value for the specific heat of a gram of the stoichiometric mixture of $1.6 \mathrm{~J} / \mathrm{g} / \mathrm{K}$ (value for basalt), the system, when perfectly isolated, would reach a temperature of $593 \mathrm{~K}$ when it starts at $298 \mathrm{~K}$. If water would be available as steam at the site, a higher end temperature could be reached. No allowance is made for the contribution of the iron end-member in this calculation. The reaction is different (see 'Methane production' section) because during the transformation, the divalent iron oxidizes to magnetite.

\section{穴


Table 1 Thermodynamic properties of substances in the reaction [3]

\begin{tabular}{ccc}
\hline Component & $\begin{array}{c}\text { Molar weight } \\
\text { (grams) }\end{array}$ & $\begin{array}{c}\text { Standard enthalpy change of } \\
\text { formation }(\mathbf{k J} / \mathbf{m o l})\end{array}$ \\
\hline Olivine & 140 & $2,170.4$ \\
$\mathrm{CO}_{2}$ (ideal gas) & 44 & 393.5 \\
$\mathrm{H}_{2} \mathrm{O}$ (liquid) & 18 & 285.8 \\
Serpentine & 276 & $4,361.7$ \\
Magnesite & 84 & $1,113.3$ \\
\hline
\end{tabular}

\section{How can this heat be used?}

It should be stressed again that the reaction proceeds slowly at low temperatures, so it is imperative that the system should have a large volume and be isolated very well to make sure that the heat that is slowly produced is not conducted or radiated away. Rocks are excellent isolating systems, so in the examples that follow, thick layers of olivine-rich rocks will be used for thermal isolation. The applications can roughly be divided into methane production, space heating, and power production.

\section{Methane production}

It has been observed that the weathering of peridotites under anoxic conditions can produce methane. Spectacular examples are the yanartași (the rock that always burns) in Turkey and los fuegos eternos (the eternal fires) in the Philippines. At the ocean floor, methane is formed by the reaction of seawater with underlying mantle rocks. What happens is the following. Olivine is a mixed crystal of $\mathrm{Mg}_{2} \mathrm{SiO}_{4}$ and $\mathrm{Fe}_{2} \mathrm{SiO}_{4}$ in a ratio of 92 to 8 in normal mantle rocks. The iron end-member under anoxic conditions reacts as follows:

$$
\begin{aligned}
6 \mathrm{Fe}_{2} \mathrm{SiO}_{4} & +1 \mathrm{CO}_{2}+2 \mathrm{H}_{2} \mathrm{O} \rightarrow 4 \mathrm{Fe}_{3} \mathrm{O}_{4} \\
& +\mathrm{CH}_{4}+6 \mathrm{SiO}_{2}
\end{aligned}
$$

When this methane leaks to the surface, it may ignite by forest fires or lightning, leading to such occurrences as found in Turkey and in the Philippines (Figure 1). It was found [4] that the methane formation is catalyzed by the tiny magnetite crystals that form as part of this reaction.

This same reaction can be used in biodigesters. The produced biogas usually has a composition of roughly $2 / 3$ methane and $1 / 3 \mathrm{CO}_{2}$, with traces of $\mathrm{H}_{2} \mathrm{~S}$. Adding olivine powder to the digesters has the following consequences:

1. Part of the $\mathrm{CO}_{2}$ in the biogas is transformed into bicarbonate. The bicarbonate dissolves in the digestate, making the biogas richer.

2. The absolute amount of produced methane increases as a consequence of reaction (3).

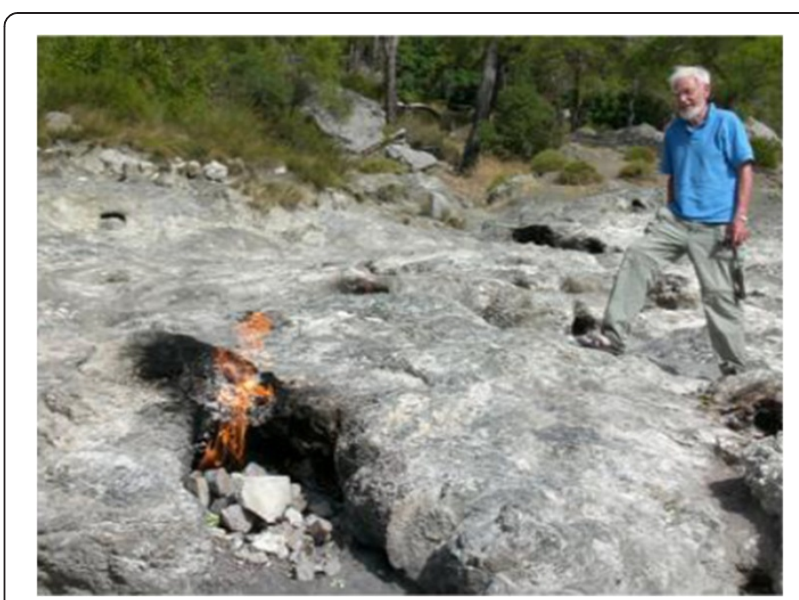

Figure 1 The yanartaşí: the rock that always burns.

3. The biodigester does not smell any more. This is also a consequence of the iron part of the olivine which reacts with the $\mathrm{H}_{2} \mathrm{~S}$ and precipitates as iron sulfides.

So, adding olivine powder to the biodigesters produces a richer and cleaner biogas and captures $\mathrm{CO}_{2}$. Because the fayalite is part of the mixed crystal of olivine, it must weather exactly at the same slow rate as the magnesium endmember. The olivine reaction will not lead to any disruption of the digester system, and in the experiments, no heating effect has been observed.

\section{Space heating}

Salts (not only $\mathrm{NaCl}$ but also potassium and magnesium salts) are often mined by solution mining. This way of mining leaves, in the end large subterranean solution, holes filled with brine. These holes must remain filled with saturated brine and permanently pressurized to avoid subsidence or even collapse of the cavity. As a first step, one must install two pipes into the brine, one to pump in olivine sand, the other to remove brine. At the end, the cavity is filled with olivine sand. It will probably require some mechanical way to spread the olivine evenly in the cavity. The remaining free volume for the brine shrinks when the cavity is filled with olivine, and the displaced brine can be recovered. The cavity filled with olivine with pore water of brine forms a well-isolated system, in which one can pump warm $\mathrm{CO}_{2}$ from a nearby power station. The reaction starts slowly, but as the temperature rises due to the exothermic reaction taking place, the reaction goes faster, and one can recover hot (saline) water with which a warm swimming pool can be filled, or hot fresh water if the water is passed through a heat exchanger in the cavity. This hot water can even be used for space heating. When the temperature becomes too low, the water is pumped back into the cavity. The reaction products (serpentine + magnesite) of the olivine take up a larger volume than the loose olivine sand, so the pores between the 
grains gradually close and form a rock. This new serpentinemagnesite rock can support the cavity, making permanent monitoring and pressurizing superfluous.

Greenhouses also require heating. In NE Greece, there are a number of geothermal wells used for heating greenhouses. The geothermal fluids here are rich in $\mathrm{CO}_{2}$, which is emitted to the atmosphere. If one covers the well head with a hill of olivine sand from the tailings of a nearby magnesite mine, this olivine will react with the hot geothermal fluid. The heat of this exothermal reaction is added to the geothermal heat, thus increasing the amount of heat available for the greenhouses, and the $\mathrm{CO}_{2}$ in the geothermal fluid is no longer emitted to the atmosphere but is sequestered by the olivine reaction and sustainably stored.

A potentially attractive application for tourists could be the following. In the sea around the island of Milos (and for a part on the island itself), large volumes of hot $\mathrm{CO}_{2}$ are bubbling from the floor of the shallow sea [5].

It is estimated that every year, about 2.2 million tons of $\mathrm{CO}_{2}$ escape from an area of $35 \mathrm{~km}^{2}$. Evidently, the temperature of the $\mathrm{CO}_{2}$ bubbles in the sea is equal to the sea temperature, but close beneath some loose sand on the beach, the temperature rises sharply. If one digs a small hole in the beach, one must stop at arm's length to avoid burning oneself. Dumping some shiploads of olivine sand on a place with active emissions can create an island. Now, the $\mathrm{CO}_{2}$ has to find its way through the thermal isolation of the olivine, and as a consequence, this olivine sand will be heated. To the heat from the $\mathrm{CO}_{2}$ bubbles, one must add the heat from the exothermal reaction going on. The likely result of this is that it will lead to a convection system in the central part of the island. Hot water is lighter than cold water, so the hot pore water with the newly formed bicarbonate in solution will rise to the top and is replenished by cold water

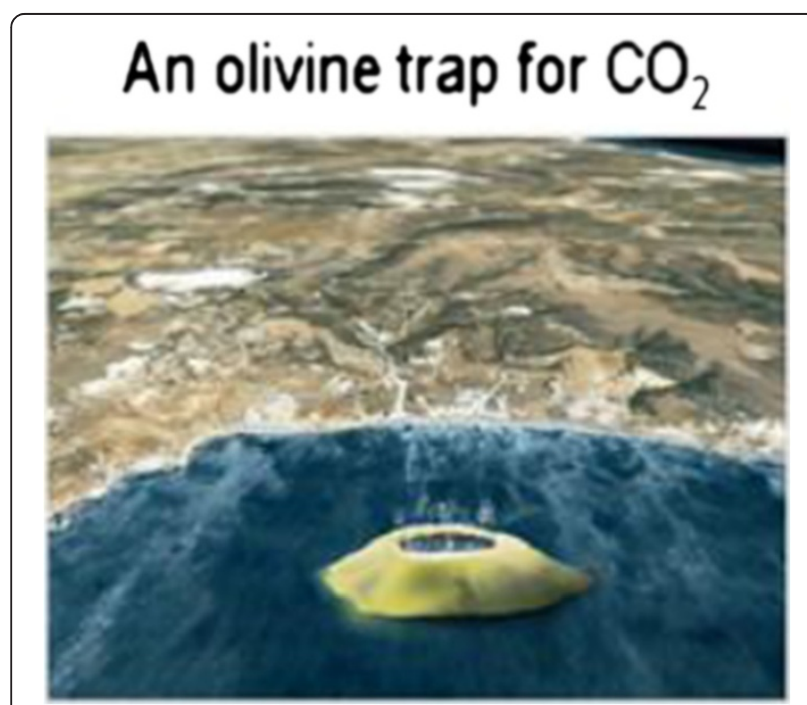

Figure 2 Artist impression of an olivine island near Milos.

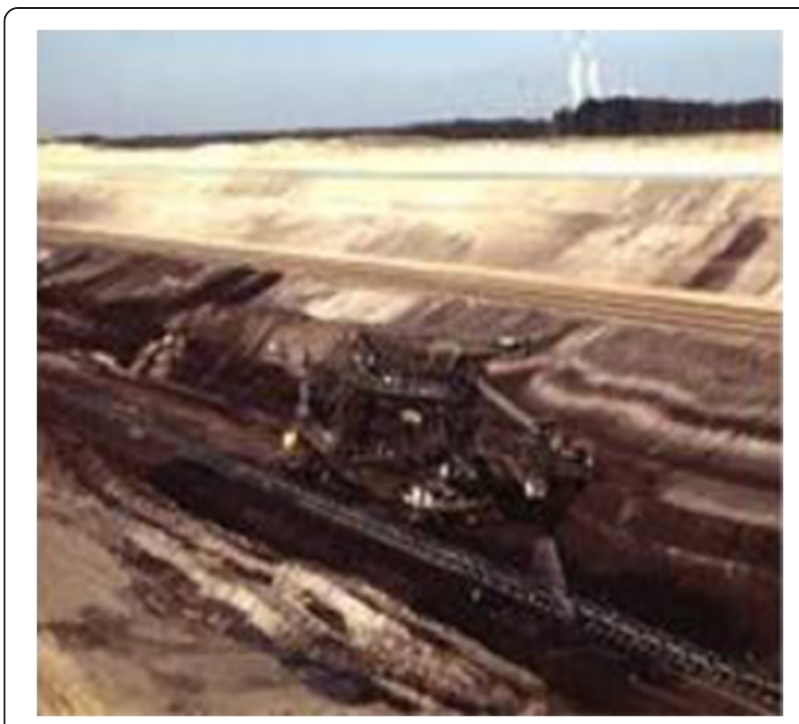

Figure 3 Lignite mines in Germany.

drawn in from the sides. If one leaves a depression in the center of the island, this will fill with warm water. It can be used by tourists as a swimming pool. While bathing in warm water, even in winter, the tourists can comfortably look out over a blue, cold Aegean Sea (Figure 2).

\section{Power production}

One can imagine a number of ways to isolate olivine during its reaction with water and $\mathrm{CO}_{2}$ and recover the produced energy. The following example will serve to demonstrate the potential use. Lignite is mined on a huge scale in the area between Aachen and Köln. The lignite is transported directly to large power plants. The mines reach a depth of over $500 \mathrm{~m}$, where thick lignite seams are mined (Figure 3). First, the overburden is removed, and after a section is mined out, it is refilled with the overburden and rehabilitated, while at the front end, the mining advances. This

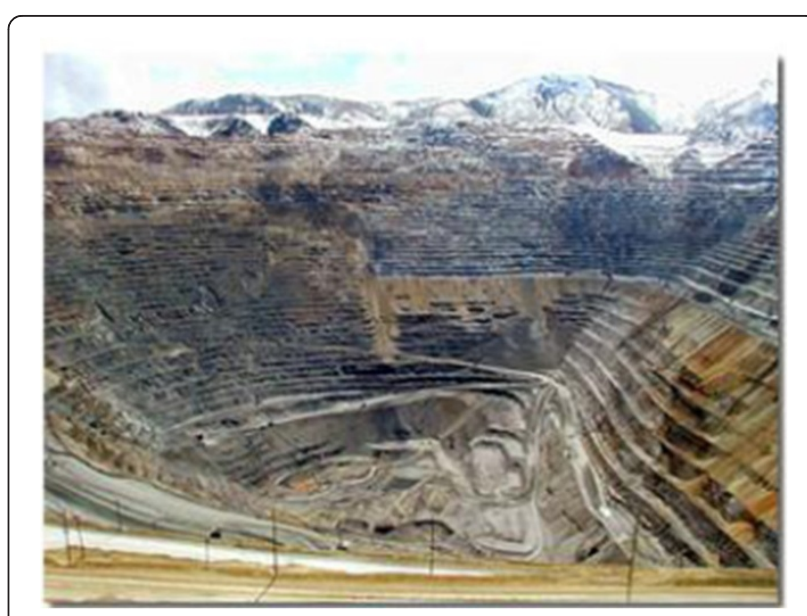

Figure 4 The world's largest open pit mine. 
means that the mine moves slowly through the landscape. If after a set of perforated pipes is laid out, the bottom $250 \mathrm{~m}$ is not filled with overburden, but with powdered olivine, this represents a huge power plant in its own right. The remaining space on top of the olivine is filled with overburden, providing the required thermal isolation. A mixture of water and $\mathrm{CO}_{2}$ (preferably fairly hot) is injected in the perforated pipe system, and as it spreads through the olivine, the reaction starts. When the temperature rises, the rate of the reaction increases. After some time, it is possible to recover high-enthalpy steam. In this way, the filling of the mined-out area with olivine sand turns it into a huge power station, providing an energy in the order of $50 \%$ of the energy produced by burning the lignite that was mined.

This approach of large-scale power production can not only be applied anywhere, where strip mining is going on, but also in abandoned large open pit mines (Figure 4). When used in this way, these will no longer be a nuisance in the landscape, and their function as a more or less natural power plant will give new life to the old mines.

\section{Conclusions}

Until now, olivine was only considered as a means to sequester $\mathrm{CO}_{2}$ by its reaction with $\mathrm{CO}_{2}$ and water. This process is known as enhanced weathering. The fact that this reaction also produces a considerable amount of energy has not yet been considered, because this heat is released too slowly for use in conventional technologies. It, therefore, does not fit into any classical system of power production. Olivine can become a supergreen fuel, however, if one fulfills the required conditions of good thermal isolation and large size of the reactant volume.

\section{Competing interests}

The author declares that he has no competing interests.

Received: 26 August 2013 Accepted: 26 August 2013

Published: 2 September 2013

\section{References}

1. Dunsmore HE (1992) A geological perspective on global warming and the possibility of carbon dioxide removal as calcium carbonate mineral. Energ Convers Manage 33:565-572

2. Schuiling RD, Krijgsman P (2006) Enhanced weathering: an effective and cheap tool to sequester $\mathrm{CO}_{2}$. Clim Change 74(1-3):349-354

3. Robie RA, Hemingway BS, Fisher JR (1978) Thermodynamic properties of minerals and related substances at $298.15 \mathrm{~K}$ and 1 Bar (10 $0^{5}$ Pascals) pressure and at higher temperatures. Geol Surv Bull 1452:456

4. Horita J, Berndt ME (1999) Abiogenic methane formation and isotope fractionation under hydrothermal conditions. Science 285:1055-1057

5. Dando PR, Hughes JA, Leahy Y, Niven SJ, Taylor LJ, Smith C (1995) Gas venting rates from submarine hydrothermal areas around the island of Milos, Hellenic Volcanic Arc. Cont Shelf Res 15(8):913-929

doi:10.1186/2192-0567-3-18

Cite this article as: Schuiling: Olivine: a supergreen fuel. Energy,

Sustainability and Society 2013 3:18.
Submit your manuscript to a SpringerOpen ${ }^{\circ}$ journal and benefit from:

- Convenient online submission

- Rigorous peer review

- Immediate publication on acceptance

- Open access: articles freely available online

- High visibility within the field

- Retaining the copyright to your article

Submit your next manuscript at $>$ springeropen.com 